\title{
Partially four-vessel umbilical cord: about a diagnosed case at Panzi hospital
}

\author{
Boengandi Walala D. ${ }^{1 *}$, Nyakio Ngeleza O. ${ }^{1}$, Mukanire Ntakwinja B. ${ }^{1}$, \\ Katenga Bosunga G. ${ }^{2}$, Mukwege Mukengere D. ${ }^{1}$
}

\begin{abstract}
${ }^{1}$ Department of Gynecology and Obstetrics, School of Medicine, Panzi Hospital, Evangelical University in Africa, Bukavu, DR Congo

${ }^{2}$ Department of Gynecology and Obstetrics, Kisangani University Clinics, School of Medicine, Kisangani University, Kisangani, DR Congo
\end{abstract}

Received: 29 October 2019

Accepted: 28 November 2019

\section{*Correspondence:}

Dr. Boengandi Walala D.,

E-mail: boengandiwalala@gmail.com

Copyright: () the author(s), publisher and licensee Medip Academy. This is an open-access article distributed under the terms of the Creative Commons Attribution Non-Commercial License, which permits unrestricted non-commercial use, distribution, and reproduction in any medium, provided the original work is properly cited.

\begin{abstract}
Umbilical cord malformations are described in the literature; and it's about the umbilical artery and the umbilical vein. There are sometimes cases of a single umbilical artery. In contrast, the number of vessels in the umbilical cord can increase by three to four. A supernumerary umbilical vein is particularly rare and is usually found in association with congenital anomalies; sometimes the supernumerary umbilical vein is associated with no malformation. We report a case of umbilical cord having a four-vessel part diagnosed at the maternity ward of Panzi Hospital, in the town of Bukavu, South Kivu, DR Congo.
\end{abstract}

Keywords: Four vessels, Panzi hospital, Umbilical cord

\section{INTRODUCTION}

The umbilical cord is a funicular stem, whitish, bumpy, surrounded by a sheath: the extension of the amnion. Inside is a mesenchymal support tissue, avascular and rich in polysaccharides, which is the Wharton jelly, in which an umbilical vein runs around which two umbilical arteries are wound..$^{1}$ In case of abnormalities, only one umbilical artery is known to be associated with intrauterine growth retardation, as well as cardiac and renal malformations. ${ }^{2}$ In contrast, the number of vessels in the umbilical cord can increase by three to four. It is more common to encounter a fourth accessory vessel of the umbilical cord than a single umbilical artery. ${ }^{3}$ Although a supernumerary umbilical vein is associated with a very high incidence of congenital abnormalities, several isolated cases of very rare supernumerary umbilical cord (two arteries and two veins) presented no fetal abnormalitie., ${ }^{4,5}$ We report a case of a partial supernumerary umbilical vein (two arteries and two veins).

\section{CASE REPORT}

This is a Congolese woman, 27 years old, having 3 years of post-secondary education, housewife, married, living in the town of Bukavu, in Ibanda commune, with the following obstetric formula: status of gravida 5, parity 5, 4 live children. She had attended 4 prenatal consultations, and her body mass index was $18 \mathrm{~kg} / \mathrm{m}^{2}$. Her pregnancy had proceeded without complications. She had no history of smoking, drinking, exposure to radiation, or other supplements and drugs. Two ultrasounds were performed during pregnancy, but they did not reveal the coexistence of a four-vessel part and a normal three-vessel part of the 
umbilical cord (GE Healthcare Logiq V5 Expert ultrasound machine with a convex transducer $3.5 \mathrm{MHz}$ ).

On September 2, 2019, at 38 weeks of amenorrhea and 3 days, she gave birth, vaginally, to a newborn male, weighing 3,600 grams, in good health, having a height of $50 \mathrm{~cm}$ and a cranial perimeter of $35 \mathrm{~cm}$, without any visible malformation. The baby's Apgar scores were 9, 10 , and 10 , respectively in the $1^{\text {st }}, 5^{\text {th }}$ and $10^{\text {th }}$ minutes. The neonatal physical examination at birth, done by a pediatrician, was normal. An ultrasound scan at the age of 30 and then 60 days revealed no anatomical or congenital abnormalities.

Upon examination of the fetal appendages at birth, the finding of a supernumerary partial umbilical vein was made (Figure 1). The fetal side of the umbilical cord included four vessels (two arteries and two veins) over a distance of $19 \mathrm{~cm}$ from the body of the newborn, while the placental side included three vessels (two arteries and one vein). Our examination of the number of vessels of the umbilical cord is done at three sites: $5 \mathrm{~cm}$ from the fetus, the middle of the umbilical cord and $5 \mathrm{~cm}$ from the placenta. The umbilical cord measured $38 \mathrm{~cm}$ long and 3 $\mathrm{cm}$ in circumference. Its insertion on the placenta was marginal. As for the membranes: they had a normal appearance, with a placental insertion circummarginata type, that is to say that there was a white ring around the chorale plate; and the short side of the membranes had measured $12 \mathrm{~cm}$.

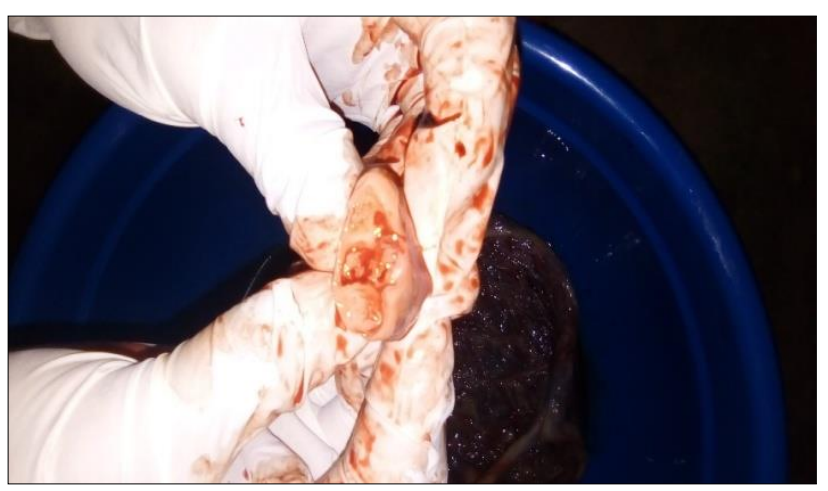

Figure 1: Four-vessel umbilical cord examination at birth.

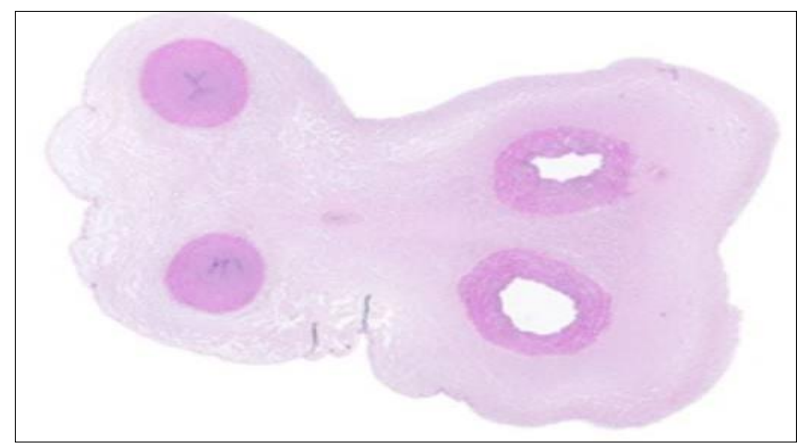

Figure 2: Histological examination.
All fetal appendices were sent to the pathology specialist for histological examination. Microscopic examination of umbilical cord cross sections obtained $1 \mathrm{~cm}$ apart and stained with hematoxylin-eosin revealed that the umbilical cord had a four-vessel part comprising two arteries and two veins (Figure 2), and that the two umbilical veins then fused, giving a portion to three vessels comprising two arteries and a vein.

The placenta weighed 344 grams, circular in shape, 20 $\mathrm{cm}$ in diameter, $2 \mathrm{~cm}$ thick in the center, and had no macroscopic and microscopic features.

\section{DISCUSSION}

The current case of an umbilical cord isolated from four vessels was diagnosed at birth. Lei et al, reported that the presence of a four-vessel umbilical cord was diagnosed before birth as the only problem in 7 out of 16 cases; in the remaining 9 cases, a four-vessel umbilical cord was diagnosed in association with intrauterine growth retardation, oligohydramnios, and various abnormalities such as bilateral cleft lip and palate, esophageal atresia, atrioventricular septal defect, right umbilical vein persistence, hypertrophic cardiomyopathy, defective thorax, and heterotaxis syndrome. ${ }^{6}$ It is difficult to diagnose an abnormal number of umbilical vessels before birth, even if other congenital anomalies coexist. While the presence of a single lateral umbilical artery to the fetal bladder makes it easy to detect a single umbilical artery, the presence of supernumerary umbilical veins tends to be neglected, as it is often difficult to control the number of umbilical veins on any the length of it.

Embryologically, in the middle of the fourth week of gestation, the sinus venosus receives blood from the right and left sinus horns. ${ }^{7,8}$ Each sinus horn receives blood from three important veins: the vitelline or omphalomenteric vein, the umbilical vein, and the common cardinal vein. ${ }^{7,8}$ During the fourth and fifth weeks of development, the sinus shifts to the right and the left sinus horn is rapidly lost. ${ }^{7,8}$ A complex pattern of vessel growth occurs, and the left vitelline and umbilical veins atrophy and disappear. ${ }^{7,8}$ Failure of this process results in a persistent right umbilical vein. ${ }^{9}$

The persistence of a right umbilical vein usually replaces the normal left umbilical vein or is supernumerary. ${ }^{10}$ Schimmel and Eidelman and Avnet et al, reported that a supernumerary umbilical vein gives an umbilical cord to four vessels. ${ }^{11,12}$ In contrast, Canavan and Hill reported that 24 of 313 infants with right umbilical vein persistence had a four-vessel umbilical cord. ${ }^{13}$ Murdoch reported an abnormal cord containing two umbilical veins and a double cord segment. ${ }^{14}$ Kurakazu, Mariko et al, reported a normal left umbilical vein with a four-vessel umbilical cord. ${ }^{15}$ Several variants of supernumerary umbilical veins have been described; however, the pathogenesis of such variations remains unknown. 


\section{CONCLUSION}

Prenatal diagnosis of umbilical cord vessels tends to be neglected. The discovery of supernumerary vessels of the umbilical cord may help in the diagnosis of other congenital malformations of the fetus. We estimate that it is important to evaluate the number of umbilical cord vessels in the second trimester using color dopplerassociated ultrasound in at least three sites: Insertion sites at the fetal abdomen and placenta, as well as the free part of the umbilical cord.

\section{ACKNOWLEDGMENTS}

Authors would like to thanks to the woman who gave her informed consent for the publication of this clinical case and all accompanying images.

\section{Funding: No funding sources}

Conflict of interest: None declared

Ethical approval: The study was approved by the Institutional of clearance committee of Evangelic University in Africa

\section{REFERENCES}

1. Nyakio N, Morphological and biometric characteristics of term fetal appendages and their obstetric implications. Final thesis. National University of Rwanda; 2009.

2. Hua M, Odibo AO, Macones GA, Roehl KA, Crane JP, Cahill AG. Single umbilical artery and its associated findings. Obstet Gynecol. 2010;115(5):930-4.

3. Meyer WW, Lind J, Moinian M. An accessory fourth vessel of the umbilical cord. A preliminary study. Am J Obstet Gynecol. 1969;105:1063-8.

4. Painter D, Russell P. Four-vessel umbilical cord associated with multiple congenital anomalies. Obstet Gynecol. 1977;50:505-7.

5. Perez-Cosio C, Sheiner E, Abramowicz JS. Fourvessel umbilical cord: not always a dire prognosis. J Ultrasound Med. 2008;27:1389-91.
6. Lei T, Xie HN, Feng JL. Prenatal diagnosis of fourvessel umbilical cord with supernumerary vein varix: a case report and literature review. J Obstet Gynaecol Res. 2017;43:1200-4.

7. Fasouliotis SJ, Achiron R, Kivilevitch Z, Yagel S. The human fetal venous system: normal embryologic, anatomic, and physiologic characteristics and developmental abnormalities. J Ultrasound Med. 2002;21:1145-58.

8. Sadler TW. Langman's medical embryology. Philadelphia: Wolters Kluwer Health/Lippincott Williams and Wilkins; 2012.

9. Blazer S, Zimmer EZ, Bronshtein M. Persistent intrahepatic right umbilical vein in the fetus: a benign anatomic variant. Obstet Gynecol. 2000;95:433-6.

10. Jeanty P. Persistent right umbilical vein: an ominous prenatal finding? Radiol. 1990;177:735-8.

11. Schimmel MS, Eidelman AI. Supernumerary umbilical vein resulting in a four-vessel umbilical cord. Am J Perinatol. 1998;15:299-301.

12. Avnet H, Shen O, Mazaki E, Yagel S, Daniel-Spiegel E. Four-vessel umbilical cord. Ultrasound Obstet Gynecol. 2011;38:604-6.

13. Canavan TP, Hill LM. Neonatal outcomes in fetuses with a persistent intrahepatic right umbilical vein. $\mathbf{J}$ Ultrasound Med. 2016;35:2237-41.

14. Murdoch DE. Umbilical-cord doubling. Report of a case. Obstet Gynecol. 1966;27:555-7.

15. Kurakazu M, Kurakazu M, Murata M, Miyamoto T, Takahashi Y, Hamasaki M, et al. A partial supernumerary umbilical vein: a case report. J Med Case Rreports. 2019;13(1):149.

Cite this article as: Walala $\mathrm{BD}$, Ngeleza NO,

Ntakwinja MB, Bosunga KG, Mukengere MD. Partially four-vessel umbilical cord: about a diagnosed case at Panzi hospital. Int J Reprod Contracept Obstet Gynecol 2020;9:450-2. 